\title{
Analytical hierarchy process for design selection of micro hot-marking tool
}

\begin{abstract}
Veracious concept selection process is crucial in design engineering where, a concept with concise description will fulfill customers' requirements. Failure in concept selection can lead to inaccurate design which will result in unnecessary process repetition of the initial stage. One of the best tools that can be used in determining the best design concept is Analytical Hierarchy Process (AHP). Micro Hot-Marking Tool (HMT) is a super-finished tool with micro tip which is to be used for alphabetical marking process using $\mathrm{CNC}$ milling machine. In this research, AHP was successfully employed in selecting design concept for HMT. Four significant and robust concepts were analyzed, namely C1, C2, C3 \& C4. Concept 2 (C2) has been chosen as the best concept with the highest score of $27 \%$ among all the evaluated concepts which will be taken into next design stage.
\end{abstract}

Keyword: AHP; Concept decision making; Design concept; Hot marking; Marking tool; Micro marking tool 